\title{
La comunicación del talento humano en la productividad empresarial
}

\section{The communication of human talent in business productivity}

\author{
Segundo José Sandoval-Ramos \\ David Alejandro Armijos-Romero \\ Karen Gabriela González-Caraguay \\ Universidad Internacional del Ecuador, Ecuador \\ Autor para correspondencia: segundo_sandoval61@ @otmail.es \\ Fecha de recepción: 20 de julio de 2018 - Fecha de aceptación: 30 de agosto de 2018
}

Resumen: La modernidad ha traído herramientas tecnológicas de comunicación que ha permitido acercar distancias, mientras que por otro lado ha distanciado a personas que se encuentran juntas, esto posiblemente ha deteriorado la comunicación humana rezagándola a un segundo plano. La comunicación humana es fundamental en la conformación de los equipos de trabajo y la eficiencia y eficacia de estos en la productividad empresarial, cumpliendo los objetivos que las empresas u organizaciones se trazan, sin embargo esta productividad se verá afectada cuando el ser humano empieza a ponerla en segundo plano deteriorando los equipos de trabajo, convirtiéndolos a estos en negligentes a la hora de cumplir con sus actividades empresariales. La metodología aplicada en el presente trabajo investigativo, consistió en la revisión, literaria de varios autores y en diferente línea que nos conduzca a un profundo análisis sobre el tema indagado. Los Resultados que se obtuvieron y según los autores analizados, estos nos indican que a la comunicación se la puede desglosar en comunicación verbal y no verbal; la primera refiere a la comunicación oral y escrita y la segunda señala: Lenguaje Paralingüístico; Lenguaje Kinésico; Lenguaje Proxémico y Lenguaje Acronímico, de los sistemas de comunicación no verbal citados los dos primeros refieren al sistema de comunicación básico primario (Fónico, Corporal) mismos que involucran sentimientos y emociones (aplicación de valores) y los restantes refieren a sistemas secundarios o culturales que actúan, modificando o reforzando el significado de los elementos de los sistemas básicos o independientemente, ofreciendo información social o cultural. De acuerdo a lo que nos indica Albert Mehrabian la comunicación verbal representa tan solo el 7\% de la comunicación humana, mientras que la comunicación no verbal representa el $93 \%$, por lo que esta se convierte en muy importante ya que las personas de forma voluntaria o involuntaria transmitimos estados de ánimo y sentimientos. Por tanto la aplicación de una buena comunicación humana genera equipos de trabajos eficientes y eficaces, y estos, conducen a la productividad empresarial, convirtiéndola a la organización en competitiva.

Palabras claves: comunicación; talento humano; productividad; empresa

Abstract: Modernity has brought technological tools of communication that have allowed to bring distances, while on the other hand it has distanced people who are together, this has possibly deteriorated human communication, leaving it in the background. The human communication is fundamental in the conformation of the work teams and the efficiency and effectiveness of these in the business productivity, fulfilling the objectives that the companies or organizations are drawn, nevertheless this productivity will be affected when the human being begins to put it in the background, deteriorating work teams, making them negligent when it comes to fulfilling their business activities. The methodology applied in the present investigative work, consisted in the revision, literary of several authors and in different line that leads us to a deep analysis on the question investigated. The results that were obtained and according to the authors analyzed, these indicate that communication can be broken down into verbal and non-verbal 
communication; the first refers to oral and written communication and the second states: Paralinguistic language; Kinesthetic language; Proxemic Language and Acronymic Language, of the non-verbal communication systems cited the first two refer to the primary basic communication system (Phonic, Corporal), which involve feelings and emotions (application of values) and the rest refer to secondary or cultural systems that they act, modify or reinforce the meaning of the elements of the basic systems or independently, offering social or cultural information. According to what Albert Mehrabian tells us, verbal communication represents only $7 \%$ of human communication, while non-verbal communication represents $93 \%$, so it becomes very important as people voluntarily or involuntary we transmit moods and feelings. Therefore, the application of good human communication generates teams of efficient and effective jobs, and these lead to business productivity, making the organization competitive.

Key Words: communication; human talent; productivity; company

\section{Introducción}

La modernidad y el ritmo actual de vida, no nos permite darle la importancia a la correcta comunicación humana, más bien, ha hecho que cada día esta se vaya deteriorando, rezagándola ignorando su importancia, al punto de que las nuevas generaciones van desconociendo la definición de comunicación humana y los pormenores que de ella se desprenden, debemos romper paradigmas y empezar a valorar la comunicación, misma que es fundamental en las relaciones humanas así lo indica Carlos Ongallo; "la comunicación es ante todo un proceso de intercambio, de información (verbal, afectiva, actitudinal...)”(Ongallo, 2007).

"La comunicación es el proceso que une a las personas para que compartan sentimientos y conocimientos, y que comprende transacciones entre ellas" (Chiavenato, 2007, pág. 59; Chiavenato, 2007) así lo dice Idalberto Chiavenato en su obra "Administración de recursos humanos, el capital humano de las organizaciones" en tal virtud podríamos decir que la comunicación es el intercambio de conocimientos y sentimientos, este último elemento es el que olvidamos especialmente en las organizaciones.

El presente trabajo investigativo tiene por objetivo generar espacios de dialogo entre quienes conforman la empresa u organización buscando una administración horizontal que motive y dinamice los equipos de trabajo. Es muy importante definir a la comunicación como un acto humano necesario que requiere de buena actitud y una gran predisposición para superar barreras que se presentan a la hora de desarrollarla para convertirla en una comunicación asertiva y efectiva, orientada a la consecución de los objetivos empresariales.

Partiendo de que no existe la no comunicación como lo determina. (P. \& D., Teoria de la Comunicacion Humana , 1991) "En primer lugar, hay una propiedad de la conducta que no podría ser más básica por lo cual suele pasársela por alto: no hay nada que sea lo contrario de conducta. En otras palabras, no hay no-conducta, o, para expresarlo de modo aún más simple, es imposible no comportarse. Ahora bien, si se acepta que toda conducta en una situación de interacción tiene un valor de mensaje, es decir, es comunicación, se deduce que por muchos que uno lo intente, no puede dejar de comunicar. Actividad o inactividad, palabras o silencio, tienen siempre valor de mensaje" 
Por consiguiente la comunicación no es un acto voluntario que se lo debe realizar cuando el emisor lo desee, existen axiomas que determinan que el ser humano aunque no quiera hablar él ya se está comunicando por consiguiente debemos analizar la comunicación desde las diferentes técnicas existentes. Por consiguiente es necesario conocer las técnicas de comunicación y expresión humana; Kinesica, Proxémica y Paralingüística que nos conduzcan a mejorar la comunicación empresarial y motivar a los equipos de trabajo y aplicar las técnicas de comunicación y expresión humana con la Kinesica, Proxémica y Paralingüística para mejorar los ambientes laborales de la empresa.

Dice el psicólogo Albert Mehrabian, que no puede faltar estudiar la comunicación no verbal. Mehrabian, actualmente profesor emérito en UCLA, llevó a cabo experimentos sobre actitudes y sentimientos y encontró, que en ciertas situaciones la comunicación verbal es altamente ambigua, solo el 7\% de la información se atribuye a las palabras (comunicación oral y escrita), mientras que el 38\% se atribuye a la voz; entonación, proyección, resonancia, tono, (comunicación Paralingüística) y el 55\% al lenguaje corporal; gestos, posturas, movimiento de los ojos, respiración (Comunicación Kinesica) y distancias personales y sociales (Comunicación Proxenica). Pág. 49.

(Mancera, s.f.) Ana María Cestero Mancera en su obra La Comunicación no Verbal y el Estudio de su Incidencia en Fenómenos Discursivos Como la Ironía incluye otro tipo de lenguaje, y nos habla de la importancia que tiene la comunicación acronímica que se define como la concepción, la estructuración y el uso que hace del tiempo el ser humano. En general se puede hablarse de tres tipos de categorías dentro del estudio del tiempo: el tiempo conceptual, el tiempo social y el tiempo interactivo.

En tal razón en la comunicación humana no solamente trasciende las palabras, esta va más allá de ellas, involucra tono de voz, movimiento corporal, distancias entre el emisor con el receptor y los tiempos que se utiliza en diferentes circunstancias por consiguiente debemos considerar con absoluta atención a la comunicación no verbal, por que como queda dicho no es importante lo que se dice si no como se lo dice

(A., 2016) Manifiesta que "Cuando empezó a estudiarse la comunicación no verbal, ésta iba dirigida a gente de ventas, gerentes y ejecutivos, pero más tarde se fue ampliando de tal manera que toda persona, cualquiera que sea su vocación y su posición social, puede usarlo para comprender mejor el acontecimiento más complejo que se presenta en la vida” Pág. 3

Una comunicación asertiva y eficiente produce equipos de trabajo dinámicos, según diversos estudiosos como los citados, la comunicación; "Fomentan una comunicación fluida entre los miembros de la empresa, así como entre éstos y las empresas externas con las que interactúa la empresa” Pág. 4 (Blanco, 2005), características y factores de implementación: Un comparativo de empresas industriales en España.

(Vera, 2011, pág. 48) José María Acosta Vera en su obra “Trabajo en equipo primera edición 2011 ESIC editorial" determina las características de que deben desarrollar los miembros del equipo entre otras autocritica; responsabilidad; lealtad; capacidad de relacionarse cordialmente con los demás miembros del equipo; iniciativa y optimismo. por lo que es de vital 
importancia desarrollar la comunicación humana en toda la complejidad que de ella se desprende, además también se debe puntualizar las ventajas de trabajar en equipo entre otras la más relevantes es la comunicación más eficaz lo dice José María Acosta Vera, que son condiciones para que el trabajo en equipo sea más eficaz favorecer la comunicación generar un clima en el que la comunicación es más fluida y positiva Pág. 85, ayuda a consolidar los equipos de trabajo convirtiéndolos dinámicos y positivos en pos de conseguir los objetivos de la organización.

La globalización cada día nos mueve con mayor prisa en un ambiente cada vez más competitivo y en todas las direcciones que la vida nos ofrece, en la actualidad no es necesario solamente ser un excelente profesional para asegurar el éxito en nuestra vida, es necesario ser un buen comunicador, saber relacionarse con el entorno de forma asertiva y eficiente, una buena comunicación nos asegura una gran motivación profesional y personal.

(Chiavenato, 2007, pág. 65) Idalberto Chiavenato en su obra Administración de Recursos Humanos, el Capital Humano de las Organizaciones; se refiere a "la conducta humana en las organizaciones; aunque las personas se pueden visualizar como recursos, es decir, como portadores de habilidades, capacidades, conocimientos, competencias, motivación para el trabajo, etc. , nunca se debe olvidar que las personas son personas, esto es portadoras de características de personalidad, expectativas, objetivos personales historias particulares, etc. Por esto, conviene destacar algunas de las características generales de las personas como personas, ya que esto mejoraría la comprensión de la conducta humana dentro de las organizaciones”.

Por estas razones debemos comprender la integralidad del talento humano con valores humanos, sentimientos y emociones; y al recurso humano lleno de formación profesional, habilidades y competencias, por tal motivo tiene aspiraciones anhelos sueños y objetivos personales de realización por cumplir.

La productividad como un elemento muy importante de la dinámica económica de las empresas y que engloba al factor humano y por tanto muy relacionado con la comunicación El Foro Económico Mundial, desde 1979, ha basado su análisis de competitividad, en el Índice de Competitividad Global (ICG), un índice muy amplio para la medición de la competitividad nacional, que capta la bases macroeconómicas y micro económicas de la competitividad nacional. Se define la competitividad como el conjunto de las instituciones, políticas y factores que determinan el nivel de productividad.

El nivel de productividad, a su vez, establece el nivel de prosperidad sostenible que puede ser percibido por la economía, en otras palabras, economías más competitivas tienden a ser capaces de producir mayores niveles de ingresos. La herramienta que sirve para realizar esta medición es un índice que combina un conjunto de doce variables, consideradas los pilares de la competitividad, y que permiten determinar el nivel de productividad de la economía y por ende el nivel de prosperidad alcanzado.

Los doce pilares que determinan la competitividad:

1. Instituciones. 
2. Infraestructura.

3. Estabilidad macroeconómica.

4. Salud y educación primaria.

5. Educación superior y entrenamiento.

6. Eficiencia en mercado de bienes.

7. Eficiencia en el mercado laboral.

8. Desarrollo del mercado financiero.

9. Preparación tecnológica.

10. Tamaño del mercado.

11. Sofisticación en los negocios.

12. Innovación.

El presente trabajo pretende analizar, una parte del pilar de competitividad, número 7) Eficiencia en el mercado laboral. La pirámide motivacional que propone (Maslow, 1991), se refiere a la satisfacción de las diferentes necesidades, que el ser humano demanda, y estas son satisfechas básicamente por las organizaciones, que se arman u organizan intencionalmente con este propósito, sin embargo, estas necesariamente están conformadas por seres humanos que en ella trabajan buscando los objetivos organizacionales o empresariales propuestos, es justamente ahí donde interactúan las personas buscando como sistemas transformar materia prima en bienes o servicios para ponerlo a disposición de los demandantes, creando y generando equipos de trabajo dinámicos donde se siente la presencia humana en su real dimensión. Es necesario puntualizar que los equipos de trabajo se apoyan en una correcta y adecuada comunicación humana situación que debe ser de una profunda preocupación de los gerentes o empresarios que buscan eficiencia y efectividad en sus empresas u organizaciones.

\section{Revisión de literatura. (Marco conceptual).}

Comunicación.- La comunicación es un proceso de intercambio de transmisión de información verbal, afectiva, actitudinal, al servicio del progreso humano.

Es muy importante definir a la comunicación como un acto humano necesario que requiere buena actitud y una gran predisposición para superar barreras que se presentan a la hora de desarrollar una comunicación asertiva y efectiva en la empresa. Partiendo de que no existe la no comunicación como lo determina (P., BeavinJ., \& D., Teoria de la Comunicacion Humana, 1991) "En primer lugar, hay una propiedad de la conducta que no podría ser más básica por lo cual suele pasársela por alto: no hay nada que sea lo contrario de conducta. En otras palabras, no hay no-conducta, o, para expresarlo de modo aún más simple, es imposible no comportarse. Ahora bien, si se acepta que toda conducta en una situación de interacción tiene un valor de mensaje, es decir, es comunicación, se deduce que por muchos que uno lo intente, no puede dejar de comunicar. Actividad o inactividad, palabras o silencio, tienen siempre valor de mensaje” Pág. 29 (Watzalawick, Bavelas, \& Jackson, 1991, pág. 29).

Por consiguiente la comunicación no es un acto voluntario porque aunque no se quiera decir algo ya se está comunicando por consiguiente debemos analizar la comunicación desde las diferentes técnicas existentes. 
(Corrales Navarro, 2011) Que al leerlo al psicólogo Albert Mehrabian no puede faltar estudiar la comunicación no verbal. Mehrabian, actualmente profesor emérito en UCLA, llevó a cabo experimentos sobre actitudes y sentimientos y encontró que en ciertas situaciones en que la comunicación verbal es altamente ambigua, solo el 7\% de la información se atribuye a las palabras, mientras que el $38 \%$ se atribuye a la voz (entonación, proyección, resonancia, tono, etc.) y el 55\% al lenguaje corporal (gestos, posturas, movimiento de los ojos, respiración, etc.). Pág. 49 (Navarro, 2011, pág. 49)

En tal razón la comunicación humana va más allá de las palabras debemos considerar con absoluta atención a la comunicación no verbal, por que como queda dicho no es importante lo que se dice si no como se lo dice

(Pease, 2016) manifiesta que "Cuando empezó a estudiarse la comunicación no verbal, ésta iba dirigida a gente de ventas, gerentes y ejecutivos, pero más tarde se fue ampliando de tal manera que toda persona, cualquiera que sea su vocación y su posición social, puede usarlo para comprender mejor el acontecimiento más complejo que se presenta en la vida” Pág. 3

La globalización cada día nos mueve con mayor prisa en un ambiente cada día más competitivo en todas las direcciones que la vida nos ofrece, en la actualidad no es necesario solamente ser un excelente profesional para asegurar el éxito en nuestra vida, es necesario ser un buen comunicador, saberse relacionar con el entorno de forma asertiva y eficiente, una buena comunicación nos asegura una gran motivación profesional y personal. Dentro de la comunicación no verbal se debe considerar tres niveles de comunicacionales y estas son:

En primer lugar la Kinésica. Son los movimientos corporales y faciales.

En segundo lugar, la Proxémica. Esta dada por la distancia física o grado de proximidad.

En tercer lugar, la Paralingüística. Es la capacidad de codificar los mensajes, a través del tono de voz. Cada uno de ellos denuncia estados de ánimo del comunicador es por ello que se debe tener muy en cuenta y considerar a la comunicación tanto personal como organizacional ya que esta generaría equipos de trabajo de alto rendimiento, generando productividad empresarial.

La productividad, es uno de los principales objetivos empresariales y que consiste en brindarle al cliente externo productos o servicios que satisfagan sus necesidades y/o exceda sus expectativas, en el momento requerido con la mejor calidad y a un precio justo.

La productividad parte de una evaluación detallada y segmentada de todas las instancias que intervienen en el proceso de conversión con propuesta de valor agregado de la materia prima e insumos en producto o servicio elaborado.

Por consiguiente podríamos definir que la productividad empresarial se define como el uso eficiente y efectivo de recursos; trabajo, capital, tierra, materiales, energía, e información en la producción de bienes y servicios.

\section{Resultados}

De acuerdo a lo que nos indica Albert Mehrabian la comunicación verbal representa tan solo en $7 \%$ de la comunicación humana mientras que la comunicación no verbal representa el 
93\% por lo que esta se convierte en muy importante ya que las personas de forma voluntaria o involuntaria transmitimos estados de ánimo y sentimientos.

Es por esta razón que la comunicación no verbal merece un análisis más profundo de la comunicación Kinésica; Proxemica y Paralingüística.

Analizaremos la comunicación Kinésica se refiere a la gesticulación facial y movimiento corporal, así tenemos:

Los gestos de la cara.- que se refiere a los movimientos de las cejas, mejillas, y nariz, hablan de poco interés, sorpresas y olores agradables y desagradables.

Movimiento de la cabeza.- aprobar o reprobar algo, interés o desinterés sobre el tema tratado o también sumisión.

La mirada.- tiene mucho que ver con la dilatación de las pupilas esta nos indica sentimientos profundos, sorpresa o agresividad, o implemente el esquivar la mirada del receptor o emisor indicaría poca sinceridad.

La sonrisa.- la sonrisa habla mucho de quienes participamos de la comunicación, se dice que nadie es tan pobre que no la merezca o tan rico que no la pueda dar todos la necesitamos ya que ella alumbra e ilumina con quien se comparte la comunicación, sin embargo debemos decir que esta deba ser extremadamente espontanea que eso demuestra sinceridad y convoca a diálogos amplios especialmente en los equipos de trabajo, porque cuando es forzada daña las relaciones en los ambientes de trabajo.

La posición de los brazos.- la posición de los brazos indica arrogancia o abatimiento que puede dañar las relaciones dentro de los equipos de trabajo.

Los movimientos de las manos.- los movimientos de las manos demuestran ansiedad o dinamismos depende del modo cómo se los realice.

La posición de las piernas.- estas demuestra comodidad o incomodidad

Como podemos ver la comunicación kinésica proporciona mucha información de manera libre que puede mejorar o dañar los ambientes organizacionales.

EI lenguaje proxémico.- se refiere a las distancias que debe existir entre en emisor y el receptos con el afán de armonizar los ambientes de trabajo, cada ser construye su propia burbuja a la que todos debemos respetar evitando invadirla ya que esta invasión se la puede considerar como falta de respeto o agresividad. El respeto de las distancias entre el emisor y el receptor genera respeto y confianza situación que armoniza y dinamiza los equipos de trabajo.

El lenguaje Paralingüístico.- este se refiere al tono de voz que en la comunicación se debe utilizar, de acuerdo a este podríamos determinar o valorar la comunicación, pudiendo demostrar; seguridad o inseguridad; confianza o desconfianza, pasividad o agresividad, todo dependerá del tono de voz que utilicemos al emitir la comunicación. 
Finalmente tenemos el lenguaje acronímico.- El tiempo también comunica, bien pasivamente, ofreciendo información cultural, bien activamente, modificando o reforzando el significado de los elementos del resto de sistemas de comunicación humana y se define como la concepción, la estructuración y el uso que hace del tiempo el ser humano. En general podemos hablar de tres tipos de categorías dentro del estudio del tiempo: el tiempo conceptual, el tiempo social y el tiempo interactivo.

Tiempo conceptual.- Forman parte de este los hábitos de comportamiento y las creencias relacionados con el concepto que tienen del tiempo las distintas culturas, por ejemplo, si lo valoran o no o si lo consideran como algo concreto o abstracto, material y tangible o intangible.

El tiempo social.- Que depende de forma directa del tiempo conceptual, está constituido por los signos culturales que muestran el manejo del tiempo en las relaciones sociales; se trabaja dentro de él, por ejemplo, la duración de determinados encuentros sociales como reuniones, entrevistas de trabajo o visitas, la estructuración de las actividades diarias tales como desayunar, comer, merendar y cenar o los momentos del día apropiados para determinadas actividades sociales.

Tiempo interactivo.- La mayor o menor duración de signos de otros sistemas de comunicación que tiene valor informativo, bien porque refuerza el significado de sus elementos o bien porque especifica o cambia su sentido. Así, son signos cronémicos, por ejemplo, la mayor o menor duración de los sonidos de algunas palabras, de algún gesto o de las pausas, con las connotaciones que conllevan, o el aumento de velocidad en la emisión de un enunciado como "no puedes hacerlo así, tienes que hacerlo...", que disminuye su efecto crítico o corrector.

Son los cuatro sistemas de comunicación no verbal reconocidos hasta el momento. De ellos, los dos primeros, uno fónico y otro corporal, son considerados sistemas básicos o primarios por su implicación directa en cualquier acto de comunicación humana, ya que se ponen en funcionamiento a la vez que el sistema verbal para producir cualquier enunciado; los otros dos, el proxémico y el cronémico, son concebidos como sistemas secundarios o culturales, dado que actúan, generalmente, modificando o reforzando el significado de los elementos de los sistemas básicos o independientemente, ofreciendo información social o cultura.

La acción del ser humano en la actividad empresarial es elemental, esta determina la calidad de empresa u organización que es, ya que su accionar es fundamental a la hora de evaluar a la empresa y está determinada por la aplicación de valores que es a lo finalmente se reduce la comunicación humana, una comunicación efectiva es la correcta aplicación de valores.

Sin embargo es necesario destacar que (Pilar, 2015) y en sus conferencias sobre "Liderazgo y emociones" nos habla de la necesidad de integrar las emociones a la fuerza laboral, este criterio requiere necesariamente de: primero de una correcta comunicación humana y segundo de la aplicación de valores, en razón de que estos elementos contribuyen a mejorar la felicidad del ser humano y una persona feliz genera equipos de trabajo eficientes y eficaces concluyendo en productividad empresarial. 
Generalmente los objetivos de la actividad empresarial siempre serán la satisfacción del cliente sin embargo debemos de puntualizar que de determinan dos clases de clientes; clientes internos y clientes externos el presente trabajo se refiere a la satisfacción y bienestar de los clientes internos como base del desarrollo empresarial ya que si disponemos de un talento humano totalmente satisfecho anímicamente y emocionalmente estos desarrollaran sus actividades organizacionales de manera dinámica generando Eficiencia del mercado laboral que a la postre contribuirá a desarrollar productividad desde la acción del talento humano ya que un trabajador motivado evitara el desperdicio de tiempos, recursos de materiales y el cuidado de los equipos maquinaria y herramientas de la empresa convirtiéndola a esta en eficiente y eficaz.

\section{Bibliografía}

A., P. (2016). El lenguaje del cuerpo . Comunicacion no verbal , 161.

Blanco, F. S. (2005). Un comparativo de empresas. El trabajo en equipo, características y factores de, 4.

Chiavenato, I. (2007). Administración de recursos humanos, el capital humano de las organizaciones. Mexico: McGAW-HILL.

Corrales Navarro, E. (2011). El Lenguaje no verbal: un proceso cognitivo superior indispensable para el ser humano revista comunicacion. Revista Comunicación, 49.

Mancera, A. M. (s.f.). La comunicación no verbal y el estudio de su incidencia en fenómenos discursios como la ironía. En A. M. Mancera, La comunicación no verbal y el estudio de su incidencia en fenómenos discursios como la ironía.

Maslow, A. (1991). Motivacion y Personalidad. Madrid: Díaz de Santos.

Navarro, E. C. (2011). El lenguaje no verbal: un proceso cognitivo superior indispensable para el ser humano. Revista Comunicación, 49.

Ongallo, C. (2007). Manual de Comunicacion. Guía para gestionar el Conocimiento, la información y las relaciones humanas en empresas y organizaciones. Madrid: Dykinson S.L.

P., W., \& D., B. B. (1991). Teoria de la Comunicacion Humana . Barcelona: Herder.

P., W., BeavinJ., \& D., L. (1991). Teoria de la Comunicacion Humana. Barcelona: Herder.

Pease, A. (2016). El lenguaje del cuerpo en la empresa, claves para interpretar la comunicación no verbal . Barcelona: Profit Editorial .

Pilar, S. (2015). Bienvenido Dolor, Una invitacion a desarrollar la voluntad de ser feliz. Barcelona: Paidos. Sordo, P. (2015). Bienvenido dolor. Una invitación a desarrollar la voluntad de ser feliz. Océano.

Vera, J. M. (2011). Trabajo en equipo. En J. M. Vera, Trabajo en equipo (pág. 48). ESIC editorial.

Watzalawick, P., Bavelas, J. B., \& Jackson, D. D. (1991). Teoría de la Comunicación Humana. En P. Watzalawick, J. B. Bavelas, \& D. D. Jackson, Teoría de la Comunicación Humana (pág. 29). Barcelona: Editorial Herder. 